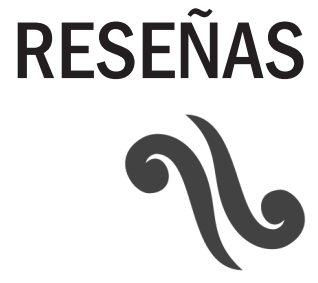





\title{
¡Ay Haití! "Hay resistencias porque hay poder" *
}

\author{
María Teresa Garzón Martínez
}

"Ay Haitî" es una canción del género pop, compuesta y producida por Carlos Jean y Dnovae, interpretada por músicas y músicos de renombre en el mundo hispano, con una intención "caritativa", pues por medio de ella se recaudan fondos para ayudar a la reconstrucción de dicho país luego del devastador terremoto de 2010. Parece que la historia de ese territorio está marcada por terremotos tanto físicos como sociales y políticos que son posibles sólo por su historia colonial y las tecnologías de poder que la misma ha creado. ${ }^{2}$ Un entramado de tenaz colonialidad y de tenaz resistencia que permanece vivo en la actualidad. Pero más allá de las canciones solidarias, los terremotos y los imaginarios que estereotipan a las personas negras haitianas como empobrecidas, qué sabemos de la isla de Bohío, Babaque o Haití, en donde se instala el primer asentamiento europeo en la Abya Yala. Qué sabemos de los procesos que dividen a la isla en dos estados nación diferentes y diferenciadas -República Dominicana y Haití. Qué sabemos de la historia reciente de racismo, blanqueamiento, procesos migratorios y relaciones "internacionales" de la isla en su historia contemporánea. ¿Por qué esto importa?

"Volver a esta tierra donde nací y me crie me genera todo tipo de sentimientos" (2021:15), afirma Ochy Curiel, autora del libro que a continuación reseñamos, al inicio de la Introducción, cuando da cuenta de manera autobiográfica de lo que significa investigar la Sentencia 168-13, emitida por el Tribunal Constitucional de República Dominicana, en el 2013, con la cual se quita la nacionalidad a por lo menos 250 mil personas nacidas en dominicana pero con ascendencia

* Reseña de la obra de Ochy Curiel, Un golpe de Estado: la Sentencia 168-13, Bogotá: En la frontera, 2021.

${ }^{2}$ El 7 de julio de 2021 fue asesinado el presidente haitiano Jovenel Moïse, de 53 años, lo que llevó al país a una nueva crisis política y social. El 14 de agosto del 2021, se presentó en ese mismo país un terremoto de 7.2 MW, dejando un elevado número de víctimas. 
haitiana, negándoles su documentación legal, abarcando un periodo de 85 años de retroactividad. Ochy nace en dominicana, pero como feminista descolonial habita varios territorios por lo que la migración no le es ajena. Entonces, desde esos múltiples lugares, Ochy se pregunta qué puede hacer para abonar a las luchas contra el racismo antihaitiano en República Dominicana, una práctica naturalizada y cotidiana, histórica y persistente. Así nace su investigación militante, con un alto compromiso ético-político, que lleva a la autora a indagar, desde diferentes y complejas aristas históricas, antropológicas del Caribe, autoetnográficas, feministas, descoloniales y antirracistas, el genocidio civil que la Sentencia 168-13 avala y con ello abona a los procesos de descolonización al tiempo que da a conocer esta terrible situación a nivel internacional en busca de una solidaridad real.

Dedicado a la memoria de Sonia Pierre, ${ }^{3}$ Un golpe de Estado: la Sentencia 168-13, en seis capítulos, un apartado introductorio y un apartado conclusivo, muestra las continuidades y discontinuidades del racismo antihaitiano en dominicana con el fin de proponer una lectura genealógica de las condiciones que permiten la emisión de una sentencia tal, cuyo objetivo es arrebatar la nacionalidad de ese país a personas de ascendencia haitiana. Para Ochy, dicha sentencia es un golpe de Estado en tanto el mismo Estado está negando e inhabilitando leyes que ha dictado con anterioridad. Para exponer sus argumentos, Ochy reseña el contexto de la colonización en la isla y la instalación del sistema esclavista, en específico, lo relacionado con el sistema de plantaciones y el establecimiento de la industria azucarera tiempo después por parte de Estados Unidos. Con ello, la autora construye una narrativa donde es posible comprender la forma en que el sistema esclavista y, poco después, la migración de mano de obra "barata" determina la historia de una isla dividida en dos naciones. Como una prolongación, Ochy reflexiona a continuación sobre los bateyes: lugares designados como habitaciones de esclavos que, con el tiempo, se transforman en comunidades rurales y semiurbanas. Se puede pensar los bateyes como apartheid espacial diseńado para mantener y perpetuar las diferencias y límites raciales y nacionales. La mayoría de las personas que dialogan con la autora en este libro han nacido en estos lugares.

Después de este contexto histórico, Ochy trabaja de lleno lo que tiene que ver propiamente con la Sentencia 168-13: sus antecedentes políticos y económicos, sus contenidos y las interpretaciones que ha suscitado en torno a los conceptos

${ }^{3}$ Nacida en 1963 y fallecida en 2011 en República Dominicana, hija de padres haitianos en situación de ilegalidad, Sonia Pierre fue una luchadora incansable por los derechos humanos y para poner fin al racismo antihaitiano. Fue la presidenta del Movimiento de Mujeres Dominico-Haitianas (MUDHA). 
de tránsito y transeúnte, determinantes aquí. A esto suma la autora la situación actual de las personas afectadas por la sentencia y las respuestas jurídicas que el gobierno dominicano en turno puso en marcha frente a la presión internacional, como lo es el Plan de regularización, sancionado por la Ley 169 del 2014, el cual sigue apostando por construir diferencias entre "extranjeros" y personas "puramente dominicanas". Esta diferencia radical entre lo Uno y lo Otro, en este caso, es rectificada por los medios de comunicación hegemónicos en dominicana, los cuales apoyan, actualizan e instalan en la opinión pública la antigua idea de "invasión” de haitianos a República Dominicana, cuestión evidente en el análisis que Ochy hace de esos medios y las élites que los hacen legítimos. Por último, porque "hay resistencias porque hay poder", como afirma la antropológa Lila Abu-Lughod (1990), la autora da cuenta de las prácticas de resistencia llevadas a cabo por las personas afectadas y sus redes de apoyo, desde la lucha pionera de Sonia Pierre hasta el movimiento más contemporáneo de Reconoci.do.

Una apuesta por descolonizar la memoria; por cuestionar profundamente los relatos que hablan de una nación nacida de la revolución de esclavos y otra nacida de la revolución de las élites criollas y blancas, cuyas diferencias en todo nivel son profundas y autoevidentes; por mostrar las continuidades de la institución esclavista en la actualidad y sus efectos sobre las personas: migración casi forzada, limbos jurídicos, apátrida; por denunciar las formas racistas de operar del Estado y sus élites en conjunción con los mecanismos de dominación a partir de los cuales se garantiza su hegemonía y se niega la ciudadanía; y, sobre todo, una apuesta por visibilizar las resistencias, aquellas cotidianas, prácticas y creativas, en las voces de las personas que han decidió continuar con la lucha y habitar en libertad aquellos territorios donde han construido sus existencias y han decidido sobrevivir. De esta manera podría resumir esta última entrega de Ochy, la cual cuenta con una hermosa diagramación, una galería fotográfica impresionante compuesta por la lente de Maribe Núñez, Juan Carlos Díaz y Raúl Zecca Castel y una terrible voluntad política que muestra, sin lugar a duda, que la investigación militante no sólo es posible en estos días, sino muy necesaria. Una investigación que parte del yo confrontado y llega al nosotros de la resistencia, un libro indispensable cuando se trata de comprender a Haití, la isla, de forma seria, crítica e informada, más allá de las canciones "caritativas". Sólo resta decir, como siempre, gracias Ochy y en ¡buenahora! 

"El mundo iluminado y yo despierta"...

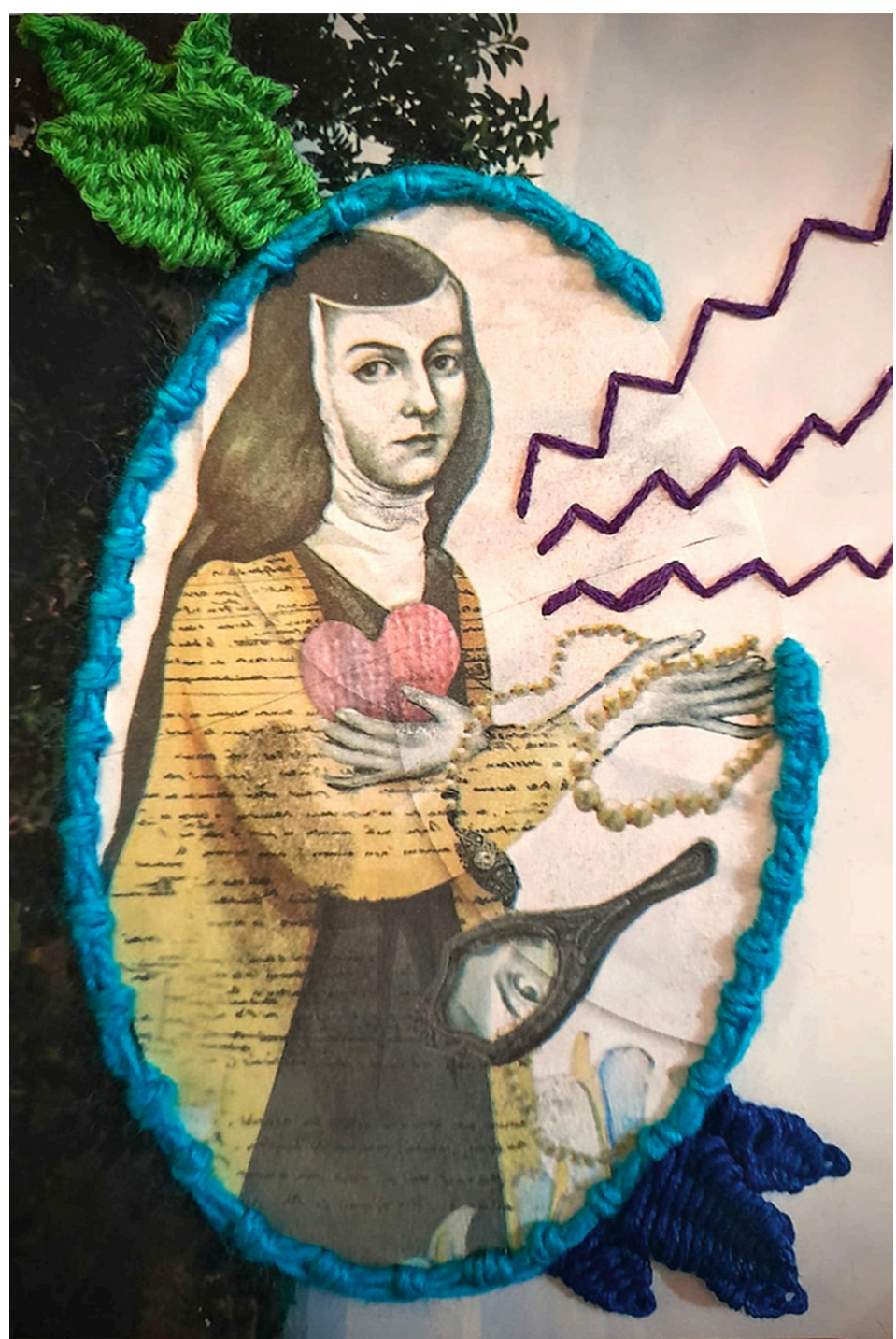


Alejandra Collado | Sor Juanita

Bordado sobre collage en fotografía

Febrero de 2021 